\title{
Two species of Strobilomyces from Jammu and Kashmir, India
}

\author{
Kour H, Kumar S and Sharma YP
}

Department of Botany, University of Jammu $J \& K$, India-180006

Kour H, Kumar S, Sharma YP 2013 - Two species of Strobilomyces from Jammu and Kashmir, India. Mycosphere 4(5), 1006-1013, Doi 10.5943/mycosphere/4/5/14

\begin{abstract}
During the systematic survey for the exploration of larger fungi of Poonch district of Jammu and Kashmir during the year 2011-2012 two species of Strobilomyces viz., S. echinocephalus and S. mollis were identified. Of these, S. echinocephalus Gelardi and Vizzini is new to India while $S$. mollis Corner is the first authentic record from the state. A key to the known species of Strobilomyces from India is also given.
\end{abstract}

Key words - Boletaceae - diversity - new record - Poonch - taxonomy

\section{Introduction}

The genus Strobilomyces Berk. (Boletaceae, Boletales) is well known for having many intricate species and is morphologically and molecularly closely related to Afroboletus Pegler \& T.W.K. Young (Nuhn et al. 2013) but differs with respect to spore characters and chemotaxonomically. The whole genus is morphologically well delimited and immediately recognizable in the field due to shaggy appearance of its sporophores which are greyish brown to blackish throughout, with conspicuous reddening or blackening of fresh tissues exposed to air (Gelardi et al. 2012). Species of Strobilomyces are mostly reported from tropical and sub-tropical areas of Asia and Africa (Chiu 1948, Heinemann 1954, Corner 1972, Pegler 1977, Ying \& Ma 1985, Zang 1985). Index Fungorum (2011) shows 60 records of this genus and recently approximately 38 species of this boletoid genus have been presented in a synoptic key given by Gelardi et al. (2012). In India, eight species of Strobilomyces are known (Murrill 1924, Bose 1946, Sharma \& Lakhanpal 1981, Manjula 1983, Lakhanpal \& Sharma 1988, Lakhanpal 1996). Among these, S. strobilaceus (Scop.) Berk. (syn S. floccopus (Vahl) P. Karst) has been reported from Jammu and Kashmir (Murrill 1924, Abraham 1991). The present paper deals with the macro- and microscopic details, seasonal occurrence and edibility status of two species belonging to genus Strobilomyces collected from Poonch district of Jammu and Kashmir.

\section{Materials \& methods}

Collections were acquired in the period August to September 2012 from the study area. Macromorphological characters were recorded from fresh specimens. Colour codes are cited according to Ridgway (1912). Microscopic analysis was made from free hand sections mounted in $5 \% \mathrm{KOH}$ and stained with 1\% Congo red and Melzer's reagent (potassium iodide $1.5 \mathrm{~g}+$ iodine 0.5 $\mathrm{g}+$ chloral hydrate $22 \mathrm{~g}+$ distilled water $20 \mathrm{ml}$ ). Microscopic line drawings were made with the aid of camera lucida (Erma, Japan) at 1000x. Sizes were determined for basidia, basidiospores, cystidia based on ocular micrometer measurement for at least 20 elements of each character. 
Microphotography was done using a Sony N50 camera attached to an Olympus CH 20i binocular microscope. Specimens were identified on the basis of critical observations of the specimen and perusal of relevant literature (Coker \& Beers 1943, Corner 1972, Soothill \& Fairhurst 1978, Smith et al. 1981, Arora 1986, Singer 1986, Lakhanpal 1996, Kaul 1997). Crystals of 1,4dichlorobenzene were used against insect infestation. The studied specimens have been deposited in the Herbarium of Botany Department, University of Jammu, Jammu.

\section{Taxonomic observations}

Strobilomyces echinocephalus Gelardi \& Vizzini (2012)

Fig. 1-2

Basidiomata medium to large. Pileus 5.5-6.0 cm wide, convex, fleshy, ornamented throughout by thin, soft, blackish scales laying upon whitish background, velar remnants hanging at the pileal edge, margins inrolled; tubes slightly decurrent, initially white then gradually turns greyish (LII.59',','f) to finally black, slightly depressed around the stipe apex; pores roundish to slightly angular. Context soft and white in the pileus and grayish black in the stipe; Stipe 9.5-10.5 $\mathrm{cm}$ long and $0.5-0.9 \mathrm{~cm}$ wide, solid, dry, fibrous, curved, equal, blackish, longitudinally ridged, covered with woolly or cottony brown to blackish floccules; Annulus absent; odour agreeable.

Basidiospores 8.8-12.8 $\times 8.0-10.4 \mu \mathrm{m}, \mathrm{a}_{\mathrm{v}} \mathrm{L}=10.8, \mathrm{a}_{\mathrm{v}} \mathrm{W}=9.2, \mathrm{Q}=1.1-1.23, \mathrm{Q}_{\mathrm{m}}=1.17$, subglobose to globose, thick walled, light yellow green to black brown (Congo red), pale brownish (water), inamyloid in Melzer's reagent, ornamented forming a complete reticulum with smooth adaxial patch. Basidia clavate, $25.6-68.8 \times 8.8-14.4 \mu \mathrm{m}$, hyaline, broad at apex becoming narrower towards the base, guttulated, 4 spored; sterigmata 4.8-9.6 $\mu \mathrm{m}$ long. Pileus cuticle hyphae 12.0-28.0 $\mu \mathrm{m}$ wide, hyaline, branched, septate, clamp connections absent. Pileus context hyphae 8.0-20.0 $\mu \mathrm{m}$ wide, branched, septate. Pleurocystidia 52.8-68.8 $\times 19.2-22.4 \mu \mathrm{m}$, hyaline, ventricose to fusiform. Stipe hyphae $8.0-18.0 \mu \mathrm{m}$ wide, septate, branched.

Habit and Habitat - solitary, scattered in the temperate forest dominated by Quercus semecarpifolia and wild Punica granatum.

Collection examined - India, Jammu and Kashmir, Poonch, Haveli, Kanuyian, humicolous, 30 August 2012, H. Kour and Y.P Sharma, BHJU - 191 (Holotype).

Edibility - Not eaten in the study area.

Distribution - Earlier reported to grow under Castanopsis orthacantha from China (Gelardi et al. 2012).

\section{Remarks}

Strobilomyces echinocephalus is characterized by having small to medium sized basidiomes, whitish surface entirely ornamented with blackish brown scales, poroid hymenophore bruising rusty-brown to blackish, stipe completely covered with woolly or cottony brown to blackish floccules. The examined specimens are in close conformity with the description given by Gelardi et al. (2012) except some differences in spore width and size of basidia (25.6-68.8 $\times 8.8-$ $14.4 \mu \mathrm{m}$ ). Besides, the identified taxon was found growing in ectomycorrhizal association (details not included) with Quercus semecarpifolia whereas earlier described species from China was found in close association with Castanopsis orthacantha.

Strobilomyces mollis Corner (1972)

Fig. 3-4

Basidiomata small to large. Pileus $2.5-8.0 \mathrm{~cm}$ wide, black, covered by appressed black scales, globose in young stage later becoming convex; tubes adnate to sub decurrent, initially grey (LIII. f) turning to black on bruising, veil present (in young specimens); pores: angular, grayish; Context firm, grayish, turning black on exposure. Stipe $3.6-9.0 \mathrm{~cm}$ long, $1.0-1.5 \mathrm{~cm}$ wide, concolorous with the pileus, dry, longitudinally striped, solid, equal, floccose, stipe more thickened as compared to pileus diameter; annulus absent. Odour agreeable. 

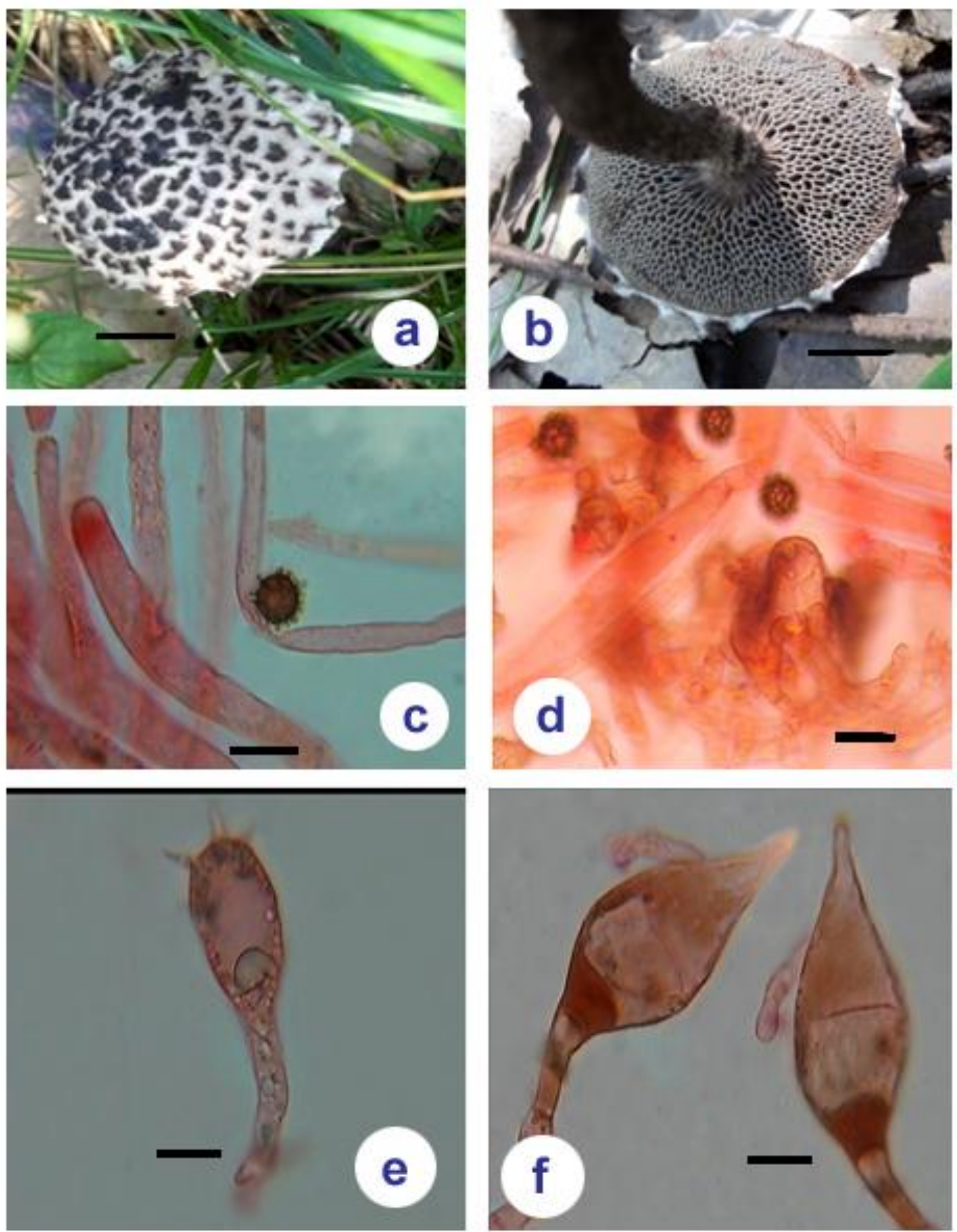

Fig. 1 - Strobilomyces echinocephalus a Fruiting body in natural habitat. b Ventral view of fruiting body showing pores and velar remnants. $\mathrm{c}-\mathrm{d}$ Basidiospores in Congo red. e Basidia. f Pleurocystidia. - Bars: $\mathrm{a}-\mathrm{b}=1 \mathrm{~cm}, \mathrm{c}, \mathrm{d}, \mathrm{e}, \mathrm{f}=10 \mu \mathrm{m}$

Basidiospores 8.8-11.2 × 8.0-10.4 $\mu \mathrm{m}, \mathrm{a}_{\mathrm{v}} \mathrm{L}=10, \mathrm{a}_{\mathrm{v}} \mathrm{W}=9.2, \mathrm{Q}=1.1-1.07, \mathrm{Qm}=1.08$, thick walled, highly ornamented forming a reticulate pattern, globose to sub globose in shape, yellow green (in iodine and Congo red) with smooth adaxial patch, inamyloid, yellowish brown in Melzer's reagent. Basidia clavate, 38.4-56.0 × 20.0-24.0 $\mu \mathrm{m}$, hyaline, guttated, broad at apex becoming narrow towards the base; Sterigmata: 2 to 4 in number, 8.0-12.0 $\mu \mathrm{m}$ long. Pileus hyphae 10.0-18.0 $\mu \mathrm{m}$ wide, septate, hyaline, less branched. Cystidia 48.0-57.6 $\times 12.8-19.2 \mu \mathrm{m}$, hyaline, ventricose-fusiform to lanceolate; veil hyphal elements hyaline, septate, $20.0-40.0 \times 12.0-18.0 \mu \mathrm{m}$. Stipe hyphae septate, hyaline, branched, clamp connections absent. 


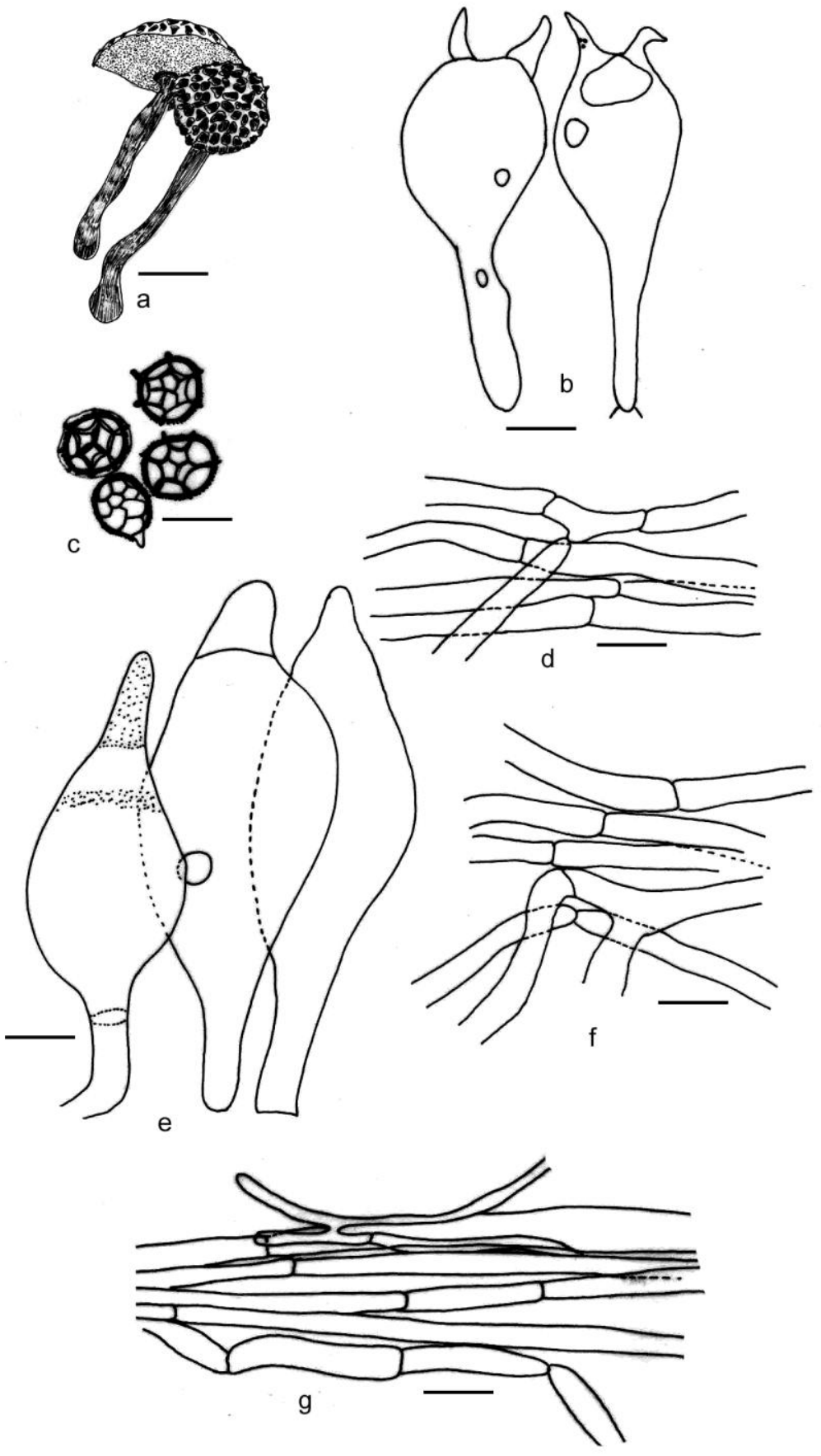

Fig. 2 - Strobilomyces echinocephalus Camera lucida drawings: a Hand drawn sporophores. b Basidia. c Basidiospores. d Pileus cuticle hyphae. e Pleurocystidia. f Pileus context hyphae. g Stipe hyphae. - Bars: $\mathrm{a}=2 \mathrm{~cm}, \mathrm{~b}-\mathrm{g}=10 \mu \mathrm{m})$.

Habit and Habitat - solitary, scattered in the mixed coniferous forests under the canopy of Pinus roxburghii and $P$. wallichiana.

Collection examined - India, J\&K, Poonch, Haveli, Krishna Ghati, humicolous, 3 September 2012, H. Kour and Y.P Sharma, BHJU - 192 (Holotype).

Edibility - Not eaten in the study area.

Distribution - Earlier reported as ectomycorrhizal with Quercus incana from Himachal Pradesh (Lakhanpal 1996). 

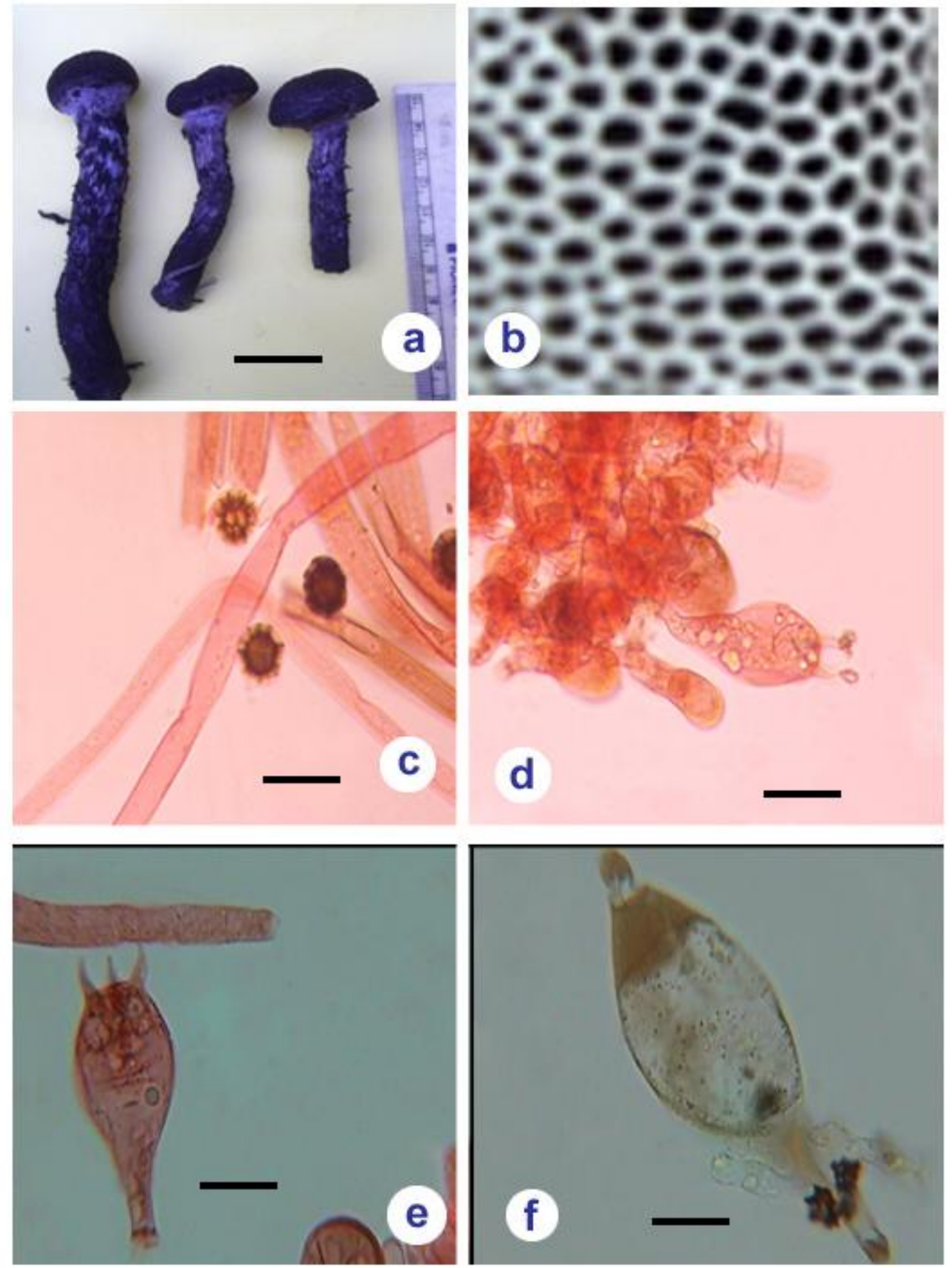

Fig. 3 - Strobilomyces mollis a Fruiting bodies. b Enlarged view of angular pores. c Basidiospores. d-e Basidia. f Cystidia. - Bars: $\mathrm{a}=3 \mathrm{~cm}, \mathrm{c}, \mathrm{d}, \mathrm{e}, \mathrm{f}=15 \mu \mathrm{m}$

\section{Remarks}

Strobilomyces mollis differs from $S$. velutipes Cooke \& Massee in having large conical warts and vinaceous tint of pileus. The small spore size differentiates it from S. nigricans Berk. Horak (1980) compared Strobilomyces montosus Berk. to S. mollis Corner and found it to resemble in all other macroscopic and microscopic features except for the size of spores $(9.0-13.0 \mu \mathrm{m})$. The examined specimen differs from S. montosus in having larger basidia $(38.4-56.0 \times 20.0-24.0 \mu \mathrm{m})$, cystidia (48.0-57.6 × 12.8-19.2) and the basidiospores $(8.8-11.2 \times 8.0-10.4 \mu \mathrm{m})$. 

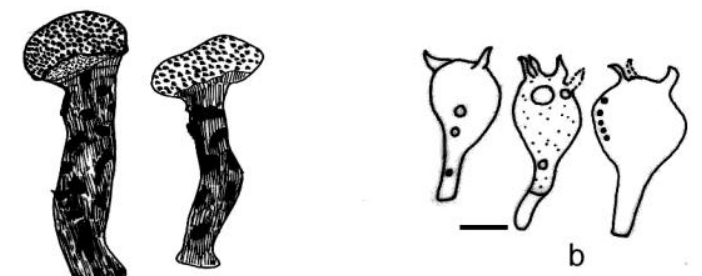

a du
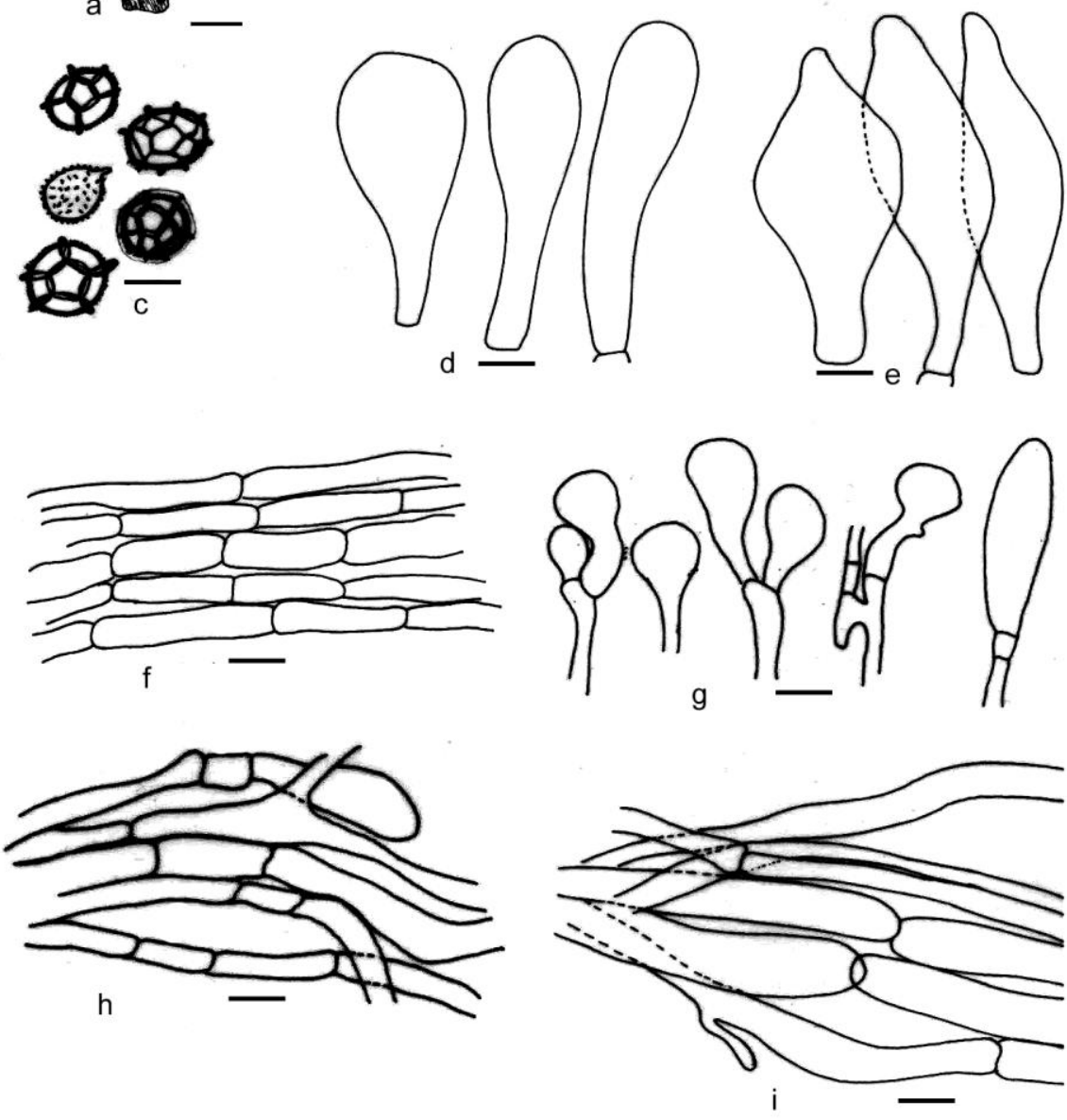

Fig. 4 - Strobilomyces mollis Camera lucida drawings: a Hand drawn sporophores. b Basidia. c Basidiopores. d-e Cystidia f Pileus cuticle hyphae. g Velar elements h Pileus context hyphae. i Stipe hyphae - Bars: $a=2 \mathrm{~cm}, \mathrm{~b}-\mathrm{i}=10 \mu \mathrm{m})$.

\section{Key to the species of Strobilomyces in India}

1. Stipe with annulus

1. Stipe without annulus

2a. Pileus 6-20 cm broad and covered by large, polygonal imbricate persistent blackish scales, hymenophore and context staining reddish then black on exposure; tubes sinuate; spores 8.5 (9.5)$14.0(15) \times(7.5) 8.5-12.0(13) \mu \mathrm{m}$

Strobilomyces strobilaceus (Scop.) Berk. 2b. Pileus 10-13 cm broad, vinaceous drab with darker, soft, friable warts covered by brown, erect, soft, conical warts, stipe with ample membranous ring; tubes adnate; spores 11.5-13.0 (15) $\times$ 9.5-11.0 (12) S. annulatus Corner

3. Spores with complete reticulum

3. Spores with incomplete reticulum .... 
4a. Pileus $2.0-7.0 \mathrm{~cm}$ broad, covered by dark, vinaceus erect, soft conical warts, context and hymenophore staining reddish then black on exposure, spores 9.0-10.5 $\times 7.5-9.0 \mu \mathrm{m}$, tubes sinuate to sub decurrent

S. mollis Corner 4b. Pileus $4.9-5.4 \mathrm{~cm}$ broad, ornamented by thin and scattered, blackish spiny scales on a whitish background, spores (6.7) 8.0-11.5 (12.8) × (6.1) 6.8-9.9 (11.5) $\mu \mathrm{m}$, ornamented forming a complete reticulum with smooth adaxial patch

S. echinocephalus Gelardi \& Vizzini 5a. Pileus and stipe dark purple brown then blackish, pileus $6.5 \mathrm{~cm}$ broad having rough hexagonal scales at the centre; tubes sinuate; stipe floccose; spores subcristate to incompletely reticulate, 12.5$15.0 \mu \mathrm{m}$

S. nigricans Berk.

5b. Pileus $4.0-8.0 \mathrm{~cm}$ broad, covered by pyramidal soft warts, tubes sinuate, margins of the pileus appendiculate, stipe without ring, nearly smooth to sub squamulose; spores verrucose to subcristate, 9.5-13.0 (14.4) × 7.0-10.0 (11.5) $\mu \mathrm{m}$

S. polypyramis Hook.

However, remaining three species namely S. indica Lloyd, S. kalimpongensis Bose and $S$. montosus Berk. are not included in this key for lack of relevant data

\section{Acknowledgement}

Authors wish to thank Prof. T.N. Lakhanpal (Himachal Pradesh University, Shimla and Dr. T.N. Kaul (Former, Director, RRL, Srinagar) from India for their generous help and suggestions. Laboratory facilities provided by the Head, Department of Botany are also acknowledged.

\section{References}

Abraham SP. 1991 - Kashmir fungal flora - An overview. Indian Mushroom Floristic Studies 13, $13-24$.

Arora D. 1986 - Mushroom Demystified: A comprehensive guide to fleshy fungi. Ten Speed Press, Berkeley, California, pp. 936.

Bose SR. 1946 - Polyporaceae of Bengal XI. Journal of Departmental Science Calcutta University 2, 53-87.

Chiu WF. 1948 - The Boletes of Yunnan. Mycologia 40, 199-231.

Coker WC, Beers AH. 1943 - The Boletaceae of North Carolina. University of North Carolina Press, Chapel Hill, pp. 95.

Corner EJH. 1972 - Boletus in Malaysia. The Botanic Gardens. Government Printing Office, Singapore, pp. 263.

Gelardi M, Vizzini A, Ercole E, Voyron S, Gang Wu, Liu XZ. 2012 - Strobilomyces echinocephalus sp. nov. (Boletales) from south-western China, and a key to the genus Strobilomyces worldwide. Mycological Progress DOI 10.1007/s 11557-012-0865-3.

Heinemann P. 1954 - Boletineae. Flore Iconographique des Champignons du Congo 3, 49-80.

Horak E .1980 - Indian Boletales and Agaricales revisions and new taxa. Sydowia 33, 88-110.

Index Fungorum 2011 - Online at:http://www.indexfungorum.org.

Kaul TN. 1997 - Introduction to mushroom science. Oxford Publishing Company, New Delhi, pp. 198.

Lakhanpal TN, Sharma R. 1988 - Fungi of North Western Himalayas-XVI, the genus Strobilomyces (Boletaceae). Kavaka 16, 27-35.

Lakhanpal TN. 1996 - Mushrooms of Indian Boletaceae.Vol. I. In: Studies in cryptogamic botany (ed Mukherji KG). APH Publishing Corporation, Delhi.

Manjula B. 1983 - A revised list of the Agarics and Boletoid basdiomycetes from India and Nepal. Proceedings of Indian Academy of Science 92, 81-213.

Murill WA. 1924 - Kashmir fungi. Mycologia 16, 133.

Nuhn ME, Binder M, Taylor, AFS, Hallingd RE, Hibbetta DS. 2013 - Phylogenetic overview of the Boletineae. Fungal Biology 117, 479-511. 
Pegler DN. 1977 - A preliminary agaric flora of east Africa. Kew Bulletin Additional Series VI. Her majesty's Stationary Office, London, U.K. pp. 615.

Ridgway R. 1912 - Colour standards and nomenclature. Washington, D.C.

Sharma JR, Lakhanpal TN. 1981 - Mycorrhiza forming species of Boletaceae. In: Proceeding symposium on forest biomass (ed Khosla PK). Indian society of tree scientists. Solan, H.P, pp. 455-457.

Singer R. 1986 - The Agaricales in modern taxonomy. Bishen Singh Mahendra Pal Singh. Dehradun, India, pp. 981.

Smith AH, Smith HV, Weber NC. 1981 - How to know the non-gilled mushrooms. Wm. C. Brown Company Publishers Dubuque, Iowa, pp. 317.

Soothill E, Fairhurst A. 1978 - The new field guide to fungi. Michael Joseph, London, pp. 191.

Ying JZ, Ma QM. 1985 - New taxa and records of the genus Strobilomyces in China. Acta Mycologica Sinica 4, 95-102.

Zang M. 1985 - Notes on the Boletales from eastern Himalayas and adjacent of China. Acta Botannica Yunnanica 7, 383-401. 